\title{
RECONSTRUCTION OF MANDIBULAR LIP AVULSION IN A CAT USING TISSUE ADHESIVE AND STANDARD WOUND CLOSURE - A CASE REPORT
}

\author{
S.P. Rathnayake ${ }^{1}$, R.A.M.K. Rathnayake ${ }^{1}$ and D.D.N. de Silva ${ }^{2}$ \\ Department of Animal Production and Health, Northern Province \\ Department of Veterinary Clinical Sciences, Faculty of Veterinary Medicine and Animal Science, University \\ of Peradeniya
}

\begin{abstract}
SUMMARY: This communication describes the reconstruction of mandibular lip avulsion in a two-year old cross-bred male cat using a tissue adhesive with the placement of horizontal mattress sutures. The cat was presented with mandibular avulsion two days after a road traffic accident. A few temporary sutures to secure the lip in place and oral antibiotics had been given by another veterinarian. However, at the time of presentation it was apparent that the sutures had been removed by the cat. As the prehension was difficult, the food intake was reported to be less than it used to be after the accident. Monomeric n-butyl-2cyanoacrylate (Surgibond) and horizontal mattress sutures with $2 / 0$ polydioxanone were applied under general anaesthesia for reconstruction. Two weeks after the intervention the patient fully recovered and started consuming food in the usual manner without any post-surgical complications.
\end{abstract}

\section{BACKGROUND}

Lip avulsion injuries have been reported in humans, dogs, cats and horses (Hague and Honnas, 1998; Rhee et al., 2004; Pope, 2006; White, 2010; Daraei et al., 2014; Vicari and Stepaniuk, 2014; Saverino and Reiter, 2018). The lower lip appears to be the structure that gets more involved in cats following vehicular trauma, animal bite or pressure trauma (Pope, 2006). Lower lip avulsion is a result of caudally or laterally directed force applied on the lower lip and the chin (Saverino and Reiter, 2018). In avulsions the lip tends to separate at the level of muco-gingival junction or at gingiva. Severity of the injury can vary depending on the force and the site at which the force is applied (White, 2010). Major bilateral avulsion to the level of the lip commissures mostly occurs due to a powerful outward force applied on the lower lip during animal bites. Falling from heights may only result in minor rostral avulsion usually at the level of the muco-gingival junction(White, 2010).

Tissue adhesives are usually used to replace standard wound closures such as sutures, staples and adhesive strips in the management of surgical and traumatic wounds (Beam, 2008). The purpose of this retrospective case report is to describe the clinical presentation and to discuss the outcome after surgical management of lower lip avulsion in a cat using a tissue adhesive in combination with standard wound closure method. Monomeric n-butyl-2-cyanoacrylate (Surgibond, SMI AG, Belgium) is a tissue adhesive which polymerizes quickly in the presence of tissue fluid. It is available as a blue colour liquid with sharp characteristic odor, translucent for facial application, which enables easy control over the quantity applied. It is indicated for lacerations, abrasions, suture/staple line sealing, post-tooth extraction, oral surgeries, etc. (Surgibond safety data sheet, 2017). It is considered that closure of lacerations with cyanoacrylate glue is a simple and fast method which acts within seconds (Pelissier et al., 2001). It has the advantage of being atraumatic and eliminates the need of suture removal in comparison with suture repair. In addition, cyanoacrylate glues form a protective barrier against microbiological organisms (Howell et al., 1995) and stop bleeding due to its ability to seal the bleeding points. This is the first case report of application of tissue glue for reconstruction of lip avulsion in cats in Sri Lanka..

\section{CASE PRESENTATION}

A two-year old, cross-bred, male cat was presented to the Vet Plus Animal Clinic, Udugampola with the complaint of mandibular lip avulsion. History revealed that the cat had met with a road traffic accident two days ago and had difficulty in prehension and mastication in spite of his desire to eat and drink. The hanging lower lip was sutured temporarily to facilitate adhesion with the mandible, and oral antibiotics with analgesics had been given by another veterinarian before it was presented for further treatment and care. At the time of presentation there was dehiscence of the lip with a few sutures hanging on the avulsed portion of the lip and the mandible (Figure 1).

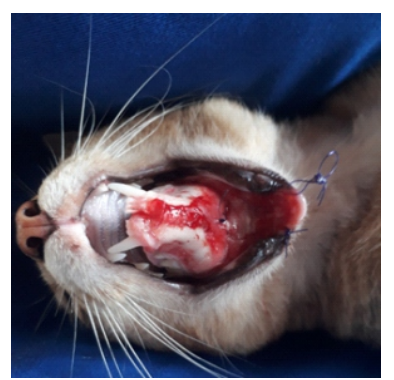

Figure 1. The cat at the time of presentation. Note the dehiscence of previously applied sutures 


\section{DIFERENTIAL DIAGNOSIS}

Differential diagnoses were mandibular symphyseal or bilateral mandibular body fracture, mandibular lip avulsion and tempero-mandibular dislocation. Oral examination by visualization and palpation ruled out fractures or dislocations. The condition was diagnosed as bilateral rostral mandibular lip avulsion. The wound was considered as a contaminated one as it was not infected due to previous antibiotic treatment.

\section{TREATMENT AND MANAGEMENT}

A thorough general clinical examination was performed. Complete blood count revealed that the patient is fit for general anesthesia to proceed with the surgical correction of the mandibular lip avulsion. Patient was kept off food for 6 hours prior to anesthesia. It was supported with intravenous fluids to compensate energy and fluid requirement and also vitamins, amino acid supplements and antibiotics were given. Meloxicam (Melox, Alina Combine Pharmaceuticals, Pakistan) was administered at the rate of $0.2 \mathrm{mg} / \mathrm{kg}$ subcutaneously as a preemptive analgesic prior to surgical intervention anticipating painless recovery.

Xylazine $\mathrm{HCl}$ (Xylazin, Dutch Farm International $\mathrm{BV}$, Holland) at $1 \mathrm{mg} / \mathrm{kg}$ was administered intra muscularly to sedate the patient, followed by Ketamine $\mathrm{HCl}$ (Ketramin, Dutch Farm International BV, Holland) at $2 \mathrm{mg} / \mathrm{kg}$ intravenously for anesthesia. After inducing general anesthesia, the patient was positioned in dorsal recumbency. The wound was debrided and thoroughly cleaned using normal saline and povidone iodine $10 \%$ solution. The tissue glue n-butyl-2cyanoacrylate (Surgibond) was applied on the exposed mandible to facilitate adhesion. The mandibular lip was repositioned ensuring obliteration of dead space and secured further by applying horizontal mattress sutures around the tooth crown of two canine teeth and incisor teeth of the lower jaw using polydioxanone $2 / 0$ (Surgical Specialties Corporation, USA) as the authors have not had previous experience in using the tissue adhesive alone on this type of avulsions (Figure 2).

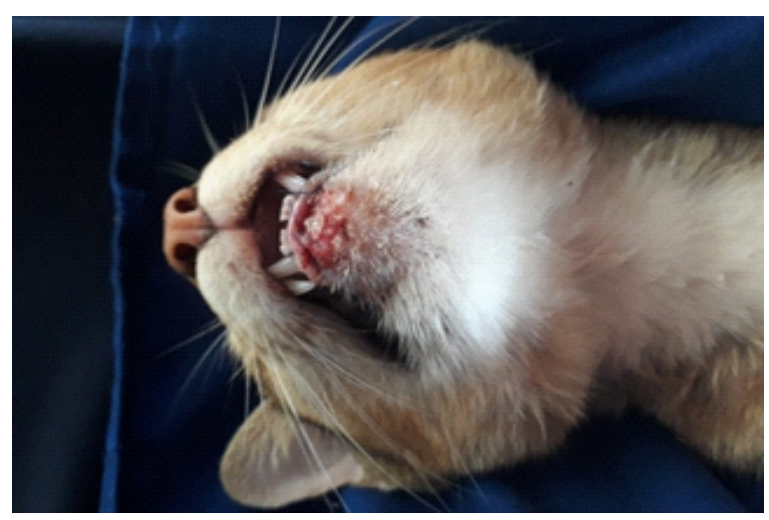

Figure 2. Appearance of the lower lip immediately after reconstruction
Post-operative care was continued with intravenous antibiotics, Cefuroxime 20mg/kg (Glaxo SmithKline, UK), Metronidazole 20mg/kg (Baxter Healthcare Ltd, UK) with supportive therapy (normal saline and 5\% dextrose) for three consecutive days and was followed by oral antibiotics. Antibacterial gel (Metrogyl Gel, Dr.Miltons Laboratories Pvt.Ltd.) was applied twice daily to avoid infections. Solid food was restricted for two weeks and only semi solid food and fluids were given orally. After two weeks, sutures were removed and it was evident that the mandibular lip was adhered to the mandible securely (Figure 3). The progress of the patient was monitored for two months for any complications but there was no evidence of complications.

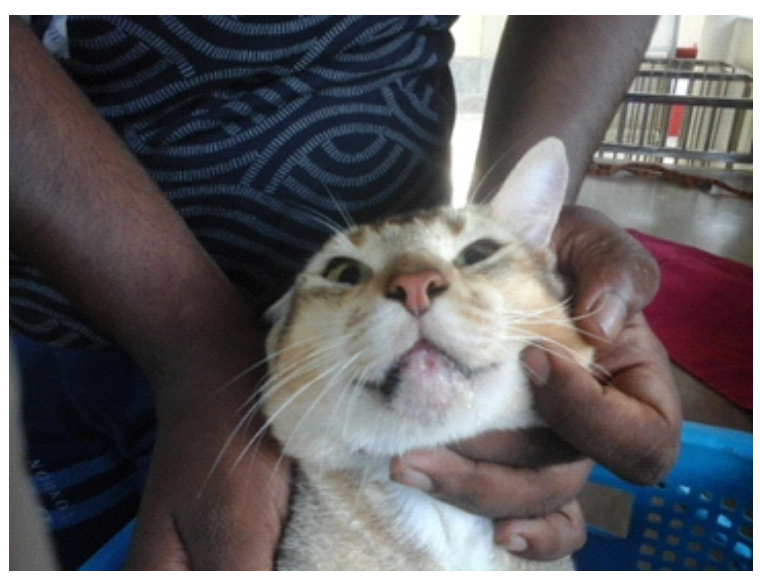

Figure 3. Two weeks after reconstruction

\section{PROGNOSIS AND OUTCOME}

Prognosis was good and the wound healed within two weeks. Patient was adapted to normal feeding pattern within this period.

\section{DISCUSSION AND CLINICAL SIGNIFICANCE}

It can be concluded that the use of tissue glue in combination with standard wound closure techniques for reconstruction of mandibular lip avulsion in cats is an effective method which assures optimum recovery. Most of the conventional wound closure methods are invasive, e.g. application of "button sutures" (de Silva, personal communication) and cause additional trauma to the skin (Annamalai et al., 2015). It could also lead to complications such as suture dehiscence, infection and cause extra pain (Quinn et al., 1997). Use of tissue glue in cats will avoid complications and in addition, it will guard against microbial infection (Howell et al., 1995) and fills the spaces where connective tissues are lost. Duration of anesthesia becomes shorter when using tissue glue in comparison to suturing alone. In the present case the suturing was done quickly as the lip was already glued to the mandible. Hence the amount of anesthetic used was less. Lesser trauma is inflicted on skin due to use of less number of sutures and thus reduces the pain experienced by the patient. There is a 
potential to use the tissue glue as the sole method of repair of lip avulsion, provided that the proper barrier/barriers are used to prevent self- inflicted trauma and mutilation.

\section{AKNOWLEDGEMENT}

Authors would like to acknowledge M.Mobius for providing tissue glue.

\section{REFERENCES}

Annamalai, S.M.N., Che' Man, Z., Ghani, N.A.A., Azlin, N., Ismail, M., Lee, C.Y., Shan, L.P. and Kampan, N. (2015). Comparing efficacy of octylcyanoacrylate adhesive glue versus polyglactin 910 sized 3/0 suture for closure of caesarean section skin incision. Journal of Obstetrics and Gynaecology Research, 4: 77.

https://doi.org/10.1111/jog.12872

Beam, J.W. (2008). Tissue adhesives for simple traumatic lacerations. Journal of Athletic Training, 43: 222-224. https://doi.org/10.4085/1062-6050-43.2.222

Daraei, P.,Calligas,J.P., Katz, E., Etra, J.W., and Sethna, A.B (2014). Reconstruction of upper lip avulsion after dog bite: Case report and review of literature.American Journal of Otolaryngology, 35: 219-225.

https://doi.org/10.1016/j.amjoto.2013.11.008

Hague, B.A. and Honnas, C.M. (1998). Traumatic dental disease and soft tissue injuries of the oral cavity. The Veterinary clinics of North America, Equine Practice, 14: 333-347.

https://doi.org/10.1016/S0749-0739(17)30201-8

Howell, J.M., Bresnahan K.A., Stair T. O., Dhindsa, H.S. and Edwards, B.A (1995).Comparison of effects of suture and cyanoacrylate tissue adhesive on bacterial counts in contaminated lacerations. Antimicrobial Agents and Chemotherapy, 39: 559-561.

https://doi.org/10.1128/AAC.39.2.559

Pelissier, P., Casoli, V., Le Bail, B., Martin, D. and Baudet, J. (2001).Internal use of n-Butyl 2cyanoacrylate (Indermil) for wound closure: An experimental study. Plastic and Reconstructive Surgery, 108: 1661-1666.

https://doi.org/10.1097/00006534-200111000-00034

Pope, E.R. (2006). Head and facial wounds in dogs and cats. Veterinary Clinics of North America - Small Animal Practice, 36: 793-817.

https://doi.org/10.1016/j.cvsm.2006.03.001
Quinn, J., Maw, J., Ramotar, K., Wenckebach, G. and Wells, G. (1997).Octylcyanoacrylate tissue adhesive versus suture wound repair in a contaminated wound model.Surgery, 122: 69-72.

https://doi.org/10.1016/S0039-6060(97)90266-X

Rhee, S.T., Colville, C. and Buchman, S.R. (2004). Conservative management of large avulsions of the lip and local landmarks. Pediatric Emergency Care, 20: 40-42.

https://doi.org/10.1097/01.pec.0000106243.72265.f6

Safety Data Sheet on Surgibond dated 2017-06-01, Manufacturer: SMI AG, Steinberg 8, 4780 St. Vith, Belgium.

Saverino, K.M. and Reiter, A.M. (2018). Clinical presentation, causes, treatment, and outcome of lip avulsion injuries in $\operatorname{dogs}$ and cats: 24 cases (2001-2017). Frontiers in Veterinary Science, 5: 1-11. https://doi.org/10.3389/fvets.2018.00144

Vicari, E. and Stepaniuk, K. (2014). Mandibular lip avulsion repair in the dog and cat. Journal of Veterinary Dentistry, 31: 168-176.

https://doi.org/10.1177/089875641403100314

White, T.L. (2010). Lip avulsion and mandibular symphyseal separation repair in an immature cat. Journal of Veterinary Dentistry, 27: 228-233. https://doi.org/10.1177/089875641002700404 